\title{
Direct economic burden of hepatitis B virus related diseases: evidence from Shandong, China
}

Jingjing Lu ${ }^{1,2}$, Aiqiang X ${ }^{1}$, Jian Wang ${ }^{2^{*}}$, Li Zhang ${ }^{1}$, Lizhi Song ${ }^{1}$, Renpeng $\mathrm{Li}^{1}$, Shunxiang Zhang ${ }^{3}$, Guihua Zhuang ${ }^{4}$ and Mingshan Lu ${ }^{5}$

\begin{abstract}
Background: Although the expenses of liver cirrhosis are covered by a critical illness fund under the current health insurance program in China, the economic burden associated with hepatitis B virus (HBV) related diseases is not well addressed. In order to provide evidence to address the economic disease burden of HBV, we conducted a survey to investigate the direct economic burden of acute and chronic hepatitis B, cirrhosis and liver cancer caused by HBV-related disease.
\end{abstract}

Methods: From April 2010 to November 2010, we conducted a survey of inpatients with HBV-related diseases and who were hospitalized for seven or more days in one of the seven tertiary and six secondary hospitals in Shandong, China. Patients were recorded consecutively within a three-to-five month time period from each sampled hospital; an in-person survey was conducted to collect demographic and socio-economic information, as well as direct medical and nonmedical expenses during the last month and last year prior to the current hospitalization. Direct medical costs included total outpatient, inpatient, and self-treatment expenditures; direct nonmedical costs included spending on nutritional supplements, transportation, and nursing. Direct medical costs during the current hospitalization were also obtained from the hospital financial database. The direct economic cost was calculated as the sum of direct medical and nonmedical costs. Our results call for the importance of implementing clinical guideline, improving system accountability, and helping secondary and smaller hospitals to improve efficiency. This has important policy implication for the on-going hospital reform in China.

Results: Our data based on inpatients with HBV-related diseases suggested that the direct cost in US dollars for acute hepatitis B, severe hepatitis B, chronic hepatitis B, compensated cirrhosis, decompensated cirrhosis and primary liver cancer was $\$ 2954, \$ 10834, \$ 4552, \$ 7400.28, \$ 6936$ and $\$ 10635$, respectively. These costs ranged from $30.72 \%$ (for acute hepatitis B) to $297.85 \%$ (for primary liver cancer) of the average annual household income in our sample. Even for patients with health insurance, direct out-of-pocket cost of all HBV-related diseases except acute hepatitis B exceeded $40.00 \%$ of the patient's disposable household income, making it a catastrophic expenditure for the household.

Conclusion: Hepatitis B imposes considerable economic burden on a family. Our findings will help health policy makers' understanding of the magnitude of the economic burden of HBV-related diseases in China. Evidence from our study also contributes to our understanding of potential benefits to society from allocating more resources to preventing and treating HBV infection, as well as increasing insurance coverage in China. These findings have important policy implications for health care reform efforts currently underway in China focusing on how to reduce the burden of catastrophic disease for its citizens.

\footnotetext{
* Correspondence: wangjiannan@sdu.edu.cn

${ }^{2}$ Shandong Center for Disease Control and Prevention, Jinan, Shandong

250014, China

Full list of author information is available at the end of the article
}

\section{Biomed Central}

(c) 2013 Lu et al.; licensee BioMed Central Ltd. This is an Open Access article distributed under the terms of the Creative Commons Attribution License (http://creativecommons.org/licenses/by/2.0), which permits unrestricted use, distribution, and reproduction in any medium, provided the original work is properly cited. 


\section{Background}

According to the fourth national socio-epidemiological survey, the prevalence of hepatitis B surface antigen among Chinese aged less than 60 was $7.20 \%$ in 2006 [1]. At present, there is no cure for chronic hepatitis B (CHB) related disease and its complications. Clinicians mainly adopt antiviral treatment or immunomodulatory methods to improve liver function, and anti-fibrosis treatment to slow down the progression of the disease. The nature of lasting and recurring conditions from HBV infection compounded by the frequency of delayed consultation impose a heavy economic burden on patients with HBV and their families. It is therefore of great policy interest whether health insurance in China is adequate in terms of reducing the economic burden for those with chronic HBV. Although the direct economic burden of $\mathrm{CHB}$ in China has been estimated in a few studies [2-6], none of these studies estimated the direct out-of-pocket cost of all HBV-related diseases, including acute hepatitis B, severe hepatitis $B$, chronic hepatitis $B$, compensated cirrhosis, decompensated cirrhosis, and primary liver cancer.

In order to fill this gap, we conducted a survey and collected information on patients from thirteen representative hospitals in Shandong, China to investigate the direct costs of HBV-related diseases and their impact on households. This study aimed to provide evidence that would contribute to our understanding of the potential benefits to society of allocating more resources to preventing and treating $\mathrm{HBV}$ infection, as well as expanding insurance coverage for those with HBV-related diseases in China. This research has important policy implications for ongoing health care reform in China aimed at reducing the economic burden of catastrophic disease for its citizens.

\section{Methods}

\section{Study population: the Shandong HBV-related inpatient} economic burden survey

Between April and November 2010, we conducted a hospital survey of inpatients with HBV-related diseases in Shangdong province, China. We first used information from the Major Epidemic Network database to identify hospitals in all seventeen cities in Shandong which treated HBV-related patients in 2010. The Department of Health's National Centre for Disease Control requires all hospitals in China to provide monthly reports of patients hospitalized for the treatment of HBV-related illness to the Major Epidemic Network. All 17 prefecture Centers for Disease Control and Prevention in Shandong province have been required to regularly report number of cases with hepatitis $B$ virus related disease through the National Notifiable Disease Surveillance System (NNDSS). This information in the NNDSS was used to partly guide our data sampling. First, out of the prefectures with the largest reported number of cases in NNDSS, we chose three prefectures Qingdao, Jinan, and Liaochang - as representative prefectures of the province. Geographically, these prefectures are located in the east, central, and west part of the province. Each represents different level of economic development: west being the most, central next, and east the least developed. Then, within each chosen prefecture, two tertiary or secondary hospitals were randomly chosen. Finally, our interviewers went sent to these selected hospitals to conduct the survey in September 2010.

In our survey, ICD-10 was used to identify eligible cases (Table 1). Inpatients were recorded consecutively within a time period of three to five months from each of the thirteen sampled hospitals. Patient sampling was ended when the number of qualified observations reached 400 in each city, except in Liaocheng where the patients totaled less than 200. Patients eligible to be included in the survey included those who were admitted into a hospital for seven or more days due to HBV-related disease and its complications, including acute hepatitis $B$, severe hepatitis $\mathrm{B}$, chronic hepatitis $\mathrm{B}$, compensated cirrhosis, decompensated cirrhosis, and primary liver cancer. The diagnostic standard in this paper for severe hepatitis B is: Prothrombin activity below $40 \%$ and serum bilirubin more than 10 times normal. We excluded patients with toxic, drug induced and immune hepatic disease, viral hepatitis caused by a secondary liver virus, as well as patients with HBV-related diseases whose hospitalization was for another reason. This resulted in a total of 949 observations in three cities (Figure 1).

Interviews were conducted by 10 trained professional investigators to collect information on both outpatient and inpatient expenses during the 12 months prior to the current hospitalization. The interviewers were six postgraduate students of the Centre for Health Management and Policy at Shandong University whose major was social

Table 1 ICD-10 codes of HBV-related diseases

\begin{tabular}{|c|c|c|}
\hline Classification & $\begin{array}{l}\text { ICD } 10 \\
\text { code }\end{array}$ & ICD 10 title \\
\hline \multirow[t]{2}{*}{ Acute hepatitis B } & B16.902 & $\begin{array}{l}\text { Acute hepatitis B } \\
\text { without icteric }\end{array}$ \\
\hline & B16.901 & $\begin{array}{c}\text { Acute hepatitis B with } \\
\text { icteric }\end{array}$ \\
\hline \multirow[t]{4}{*}{ Severe hepatitis B } & B16.906 & Severe hepatitis B \\
\hline & B16.908 & Acute Severe hepatitis B \\
\hline & B16.909 & $\begin{array}{c}\text { subacute severe } \\
\text { hepatitis B }\end{array}$ \\
\hline & B18.102 & Chronic severe hepatitis B \\
\hline $\begin{array}{l}\text { Compensated and } \\
\text { decompensated cirrhosis }\end{array}$ & K74.601 & cirrhosis of liver \\
\hline Primary liver cancer & C22.001 & $\begin{array}{l}\text { Hepatocellular } \\
\text { carcinoma }\end{array}$ \\
\hline
\end{tabular}


medicine and health management, as well as four staff members who were trained in public health with a specialty in epidemiology at the Shandong Provincial Centre for Disease Control and Prevention. Investigators explained the purposes and confidentiality of the survey, and then invited patients to participate in the survey. Respondents could choose not to participate; 894 agreed to be interviewed. Ethics approval of this study was obtained from the Shandong Provincial Centre for Disease Control and Prevention. After patients were discharged from the hospital, inpatient expenses for the most recent hospitalization were obtained from the hospital financial database.

\section{Key variables}

In the survey, the following information was collected: hospital ID, demographic information and socioeconomic status (including age, gender, education, occupation, family size, and individual and household monthly income), diagnosis (ICD-10), and health insurance status. ICD-10 is collected from the hospital nursing stating where patients are diagnosed when admission. Therefore the interviewers would have had that information ahead of time. Health insurance was categorized as insured or uninsured. Insured was defined as someone who was covered by any of the following types of health insurance programs: public insurance provided to civil servants, the basic health insurance scheme for urban employees (BHISUE) or for urban residents (BHISUR), the New Rural Cooperative Medical Scheme (NRCMS), or private insurance.

The patients were interviewed during hospitalization about their expenditures of previous hospital stays within the last 12 months. The expenditures of their current hospital stays were extracted directly from the hospital financial database right after their discharge. Direct medical costs included total outpatient and inpatient expenditures (i.e., hospitalization expenditures, nursing, prescription drugs, examination fees, etc.), and total self-treatment expenditures. Direct total costs for each patient were divided by the number of admissions if the patient had two or more hospital admissions. Direct nonmedical costs included expenditures on nutrition supplements, transportation, and patient accompaniers' costs as a result of the disease. Finally, information on inpatient expenditures for the current hospitalization was obtained from the hospital financial database. All costs are expressed in United States dollars using the June 30, 2010 exchange rate of 6.7909 RMB.

\section{Statistical analysis}

Descriptive statistics were employed to illustrate the characteristics of both insured and uninsured patients in the study population; the characteristics included sociodemographic characteristics, out-patient and inpatient expenses, direct and in-direct costs, and health insurance status. Frequencies of variables in the survey were not weighted because sampling weights were not available. A parallel and double entry method was used to input data using Epidata 3.0; direct medical and nonmedical costs were calculated. Stata 7.0 was used for the statistical analysis in this study. As the costs were non-normally distributed, the Kruskal-Wallis test was used to test for statistically significant differences.

\section{Results}

\section{Descriptive results}

A descriptive analysis of both insured and uninsured HBV-related patients is provided in Table 2. Among the 894 HBV-related patients included in our survey, 347 cases were from Jinan, 374 cases from Qingdao and 173 cases from Liaocheng. There were 849 patients (94.97\%) with insurance; 45 (5.03\%) without insurance. Most patients $(86.35 \%)$ had one of three conditions: chronic hepatitis B, compensated cirrhosis or decompensated cirrhosis. Mean age was 45.80 years and over two-thirds were male (641 or $71.70 \%)$. The insured group was older than the uninsured group (46.37 vs. 34.89). Most had obtained a high school education or above; only $19.69 \%$ were uneducated or only attended primary school. 
Table 2 Characteristics of all HBV-related diseases for insured and uninsured inpatients in Shandong province

\begin{tabular}{|c|c|c|c|}
\hline Characteristics & $\begin{array}{l}\text { All inpatients } \\
\qquad N=894\end{array}$ & $\begin{array}{l}\text { Uninsured (\%) } \\
\qquad \mathrm{N}=45\end{array}$ & $\begin{array}{c}\text { Insured (\%) } \\
\mathrm{N}=849\end{array}$ \\
\hline \multicolumn{4}{|l|}{ Location } \\
\hline Jinan & 347 & 5.19 & 94.81 \\
\hline Qingdao & 374 & 5.89 & 94.11 \\
\hline Liaocheng & 173 & 2.89 & 97.11 \\
\hline \multicolumn{4}{|l|}{ Condition } \\
\hline Acute hepatitis B & 29 & $4(13.79 \%)$ & $25(86.21 \%)$ \\
\hline Severe hepatitis B & 28 & $0(0.00 \%)$ & $28(100.00 \%)$ \\
\hline Chronic hepatitis B & 449 & $33(7.35 \%)$ & $416(92.65 \%)$ \\
\hline Compensated cirrhosis & 121 & $1(0.83 \%)$ & $120(99.17 \%)$ \\
\hline Decompensated cirrhosis & 202 & $6(2.97 \%)$ & $196(97.03 \%)$ \\
\hline Primary liver cancer & 65 & $1(1.54 \%)$ & $64(98.46 \%)$ \\
\hline Male & $71.7 \%$ & 80 & 71.26 \\
\hline Age (sd) & $45.8(13.88)$ & $34.89(12.04)$ & $46.37(13.73)$ \\
\hline \multicolumn{4}{|l|}{ Education } \\
\hline Uneducated and primary school & 19.69 & 8.89 & 20.26 \\
\hline High school & 60.74 & 57.78 & 60.90 \\
\hline College & 18.57 & 28.89 & 18.02 \\
\hline Graduate & 1.01 & 4.44 & 0.82 \\
\hline household monthly income (sd) & $438(464)$ & $411(325)$ & $439(470)$ \\
\hline Patient monthly income (sd) & $190(201)$ & $191(220)$ & 190 (201) \\
\hline
\end{tabular}

*Notes:

1. Monetary values reported in US dollars. 1 US dollar =6.7909 RMB (exchange rate on Jun 30th, 2010).

2. Standard deviation is reported in the parentheses.

Household monthly income was $\$ 438$ for the overall sample; $\$ 439$ for the insured and $\$ 411$ for the uninsured group. Individual monthly income was $\$ 190$ for the overall sample; $\$ 190$ for the insured and $\$ 191$ for the uninsured.

\section{Direct cost}

Direct total costs for each patient were divided by the number of admissions if the patient had two or more hospital admissions. As shown in Table 3, the direct costs for acute hepatitis B, severe hepatitis B, chronic hepatitis B, compensated cirrhosis, decompensated cirrhosis, and primary liver cancer were \$2954, \$10834, \$4552, \$7400, \$6937, and \$10636 respectively. Direct costs for inpatients who were insured were higher than for the uninsured. Proportion of direct medical cost (\%) is consistently high, accounting for $91-97 \%$ in direct cost. For insured patients, there was a significant difference in the direct costs among the HBV-related diseases with primary liver cancer costing much more.

The direct medical cost of acute hepatitis $B$, severe hepatitis B, chronic hepatitis B, compensated cirrhosis, decompensated cirrhosis, and primary liver cancer was \$2854, \$10114, \$4136, \$6781, \$6400, and \$9891, respectively. As shown in Table 4, outpatient expenditures were highest for primary liver cancer (\$1476), followed by decompensated cirrhosis and compensated cirrhosis at $\$ 958$ and $\$ 951$, respectively. Hospitalization stay expenditures were highest for severe hepatitis B and primary liver cancer, $\$ 9367$ and $\$ 8209$ respectively, followed by compensated cirrhosis and decompensated cirrhosis, $\$ 5762$ and $\$ 5355$, respectively. As for selftreatment expenditures, primary liver cancer and severe

Table 3 Inpatient direct costs of all HBV-related diseases (dollar/per admission)

\begin{tabular}{lccc}
\hline Classification & \multicolumn{3}{c}{ Direct cost } \\
\cline { 2 - 4 } & Insured & Uninsured & Overall mean \\
\hline acute hepatitis B & 3098 & 2056 & 2954 \\
severe hepatitis B & 10834 & - & 10834 \\
chronic hepatitis B & 4689 & 2825 & 4552 \\
compensated cirrhosis & 7451 & 1311 & 7400 \\
decompensated cirrhosis & 7046 & 3359 & 6937 \\
primary liver cancer & 10769 & 2099 & 10636 \\
$x^{2}$ & $\mathbf{1 2 7 . 8 7}$ & $\mathbf{3 . 6 6}$ & $\mathbf{1 3 5 . 4 7}$ \\
$P$ & $\mathbf{0 . 0 0 0 1}$ & $\mathbf{0 . 4 5 3 8}$ & $\mathbf{0 . 0 0 0 1}$ \\
\hline
\end{tabular}


Table 4 Direct medical cost of all HBV-related diseases (dollar/per annual average admission)

\begin{tabular}{|c|c|c|c|c|}
\hline Classification & Outpatient expenditure & Hospitalization stay expenditure & Self-treatment expenditure & Total \\
\hline Acute hepatitis & 109 & 2741 & 4 & 2854 \\
\hline B (median) & $(60)$ & $(2332)$ & $(0)$ & $(2363)$ \\
\hline Severe hepatitis & 557 & 9367 & 191 & 10114 \\
\hline B (median) & $(265)$ & (9395) & $(0)$ & (9426) \\
\hline Chronic hepatitis & 615 & 3508 & 13 & 4136 \\
\hline B (median) & $(133)$ & (2215) & (0) & $(2745)$ \\
\hline Compensated & 951 & 5762 & 67 & 6781 \\
\hline cirrhosis (median) & $(996)$ & $(3152)$ & (0) & $(3811)$ \\
\hline Decompensated & 958 & 5355 & 88 & 6400 \\
\hline cirrhosis (median) & $(305)$ & (3754) & (0) & $(4541)$ \\
\hline Primary liver & 1476 & 8209 & 206 & 9891 \\
\hline cancer (median) & (449) & (5941) & (0) & $(7260)$ \\
\hline$x^{2}$ & 41.87 & 126.01 & 24.76 & 131.63 \\
\hline$P$ & 0.0001 & 0.0001 & 0.0002 & 0.0001 \\
\hline
\end{tabular}

hepatitis B were the highest, estimated to be $\$ 206$ and $\$ 191$, respectively. Uninsured patients reported almost no self-treatment expenses. For insured patients, direct medical costs differed significantly among the six HBVrelated conditions, with the highest spending being for severe hepatitis B $(\$ 10114$. Clearly this disease has a major impact in terms of healthcare costs.

The study found that the direct nonmedical cost of acute hepatitis $B$, severe hepatitis $B$, chronic hepatitis $B$, compensated cirrhosis, decompensated cirrhosis and primary liver cancer, was $\$ 100, \$ 719, \$ 416, \$ 619, \$ 536$ and $\$ 745$. Transportation costs were $\$ 83, \$ 537, \$ 113, \$ 235$, $\$ 230$ and \$494, respectively, and were higher for insured versus uninsured patients.. Nutrition expenses were $\$ 16$, $\$ 170, \$ 302,383, \$ 303$ and $\$ 251$, respectively. There were no statistically significant differences in the direct nonmedical cost of HBV-related diseases among those who did not have insurance. However, direct nonmedical costs of those who had insurance were highest for patient's primary liver cancer.

\section{Impact of disease burden on a household}

The direct economic burden of HBV-related diseases and their impact on a household were illustrated in Table 5. The direct cost of HBV-related diseases as a proportion of annual family income ranged from 30.72\% for those with acute Hepatitis B to $297.85 \%$ for those with primary liver cancer. Even after reimbursement, the direct cost of patients who experienced severe hepatitis $B$, chronic hepatitis $B$, compensated cirrhosis, decompensated cirrhosis, and primary liver cancer exceeded $40.00 \%$ of disposal household income. The economic burden was significantly different among the six diseases for insured patients.

\section{Re-analyses after excluding the $\mathbf{4 5}$ uninsured patients}

We re-ran the analyses after excluding the 45 uninsured patients since some of the conditions were either not represented (severe hepatitis B) or have very few patients (acute hepatitis B, compensated cirrhosis, primary liver cancer) among uninsured patients (Table 2). In this analysis, costs were stratified by level of care since costs may differ between tertiary and secondary hospitals.

As shown in Table 6, the direct cost for acute hepatitis $B$, severe hepatitis $B$, chronic hepatitis $B$, compensated cirrhosis, decompensated cirrhosis, and primary liver cancer in tertiary hospitals was \$3135, \$10834, \$4380, $\$ 6022, \$ 7107$, and $\$ 10213$ respectively. The direct cost for acute hepatitis B, chronic hepatitis B, compensated cirrhosis, decompensated cirrhosis, and primary liver cancer in secondary hospitals was $\$ 1388, \$ 5588, \$ 19919$, $\$ 6565$, and $\$ 13268$, respectively. The direct costs for acute hepatitis B were significantly higher in tertiary hospitals compared to secondary hospitals $\left(x^{2}=4.31\right.$, $P=0.0378$ ), whereas the opposite was true for those with chronic hepatitis $\mathrm{B}\left(x^{2}=12.12, P=0.0005\right)$.

As shown in Table 6, median cost of patients with acute hepatitis B treated in secondary hospitals is significantly lower than those treated in tertiary hospitals (1388 vs. $3135, \mathrm{p}<0.04)$. ). It should be noted, however, that the sample size of patients with acute hepatitis B treated in secondary hospitals is quite low (3 only) and the results on cost comparison may not be meaningful. For patients with chronic hepatitis B however, 64 were treated in secondary hospitals and 385 in tertiary hospitals. The median 
Table 5 The impact of disease burden on a household (dollar/per annual average admission)

\begin{tabular}{|c|c|c|c|c|c|c|c|c|c|c|c|}
\hline \multirow[t]{2}{*}{ Classification } & \multicolumn{4}{|c|}{ Direct cost } & \multicolumn{3}{|c|}{ Annual household income } & \multicolumn{4}{|c|}{ Percent of direct cost in annual household income (\%) } \\
\hline & $\begin{array}{l}\text { Insured (before } \\
\text { reimbursement) }\end{array}$ & $\begin{array}{l}\text { Insured (after } \\
\text { reimbursement) }\end{array}$ & Uninsured & Overall & Insured & Uninsured & Overall & $\begin{array}{l}\text { Insured (before } \\
\text { reimbursement) }\end{array}$ & $\begin{array}{l}\text { Insured (after } \\
\text { reimbursement) }\end{array}$ & Uninsured & Overall \\
\hline \multirow{2}{*}{$\begin{array}{l}\text { acute hepatitis } \\
\text { B (median) }\end{array}$} & 3098 & 1549 & 2056 & 2954 & 10171 & 6141 & 9615 & 30.46 & 15.23 & 33.48 & 30.72 \\
\hline & (2779) & (1389) & (1469) & $(2464)$ & $(5301)$ & (5213) & $(5301)$ & $(52.42)$ & $(26.21)$ & (28.18) & (46.49) \\
\hline \multirow{2}{*}{$\begin{array}{l}\text { severe hepatitis } \\
\text { B (median) }\end{array}$} & 10834 & 5417 & - & 10834 & 3941 & - & 3941 & 274.89 & 137.45 & - & 274.89 \\
\hline & (9699) & (4849) & & (9697) & (3534) & & (3534) & (274.42) & (137.20) & & (174.39) \\
\hline \multirow{2}{*}{$\begin{array}{l}\text { chronic hepatitis } \\
\text { B (median) }\end{array}$} & 4689 & 2345 & 2825 & 4552 & 5824 & 5191 & 5778 & 80.52 & 40.26 & 54.42 & 78.79 \\
\hline & (2978) & (1489) & (2673) & (2919) & (4418) & $(4241)$ & (4418) & $(67.41)$ & (33.70) & $(63.02)$ & (66.07) \\
\hline \multirow{2}{*}{$\begin{array}{l}\text { compensated } \\
\text { cirrhosis (median) }\end{array}$} & 7451. & 3726 & 1311 & 7400 & 5297 & 3534 & 5282 & 140.67 & 70.34 & 37.09 & 140.10 \\
\hline & (4116) & (2058) & $(0.00)$ & (4074) & (3711) & (3534) & (3711) & $(110.93)$ & (55.46) & (37.09) & (109.77) \\
\hline \multirow{2}{*}{$\begin{array}{l}\text { decompensated } \\
\text { cirrhosis (median) }\end{array}$} & 7046 & 3523 & 3359 & 6937 & 4187 & 3475 & 4166 & 168.30 & 84.15 & 96.65 & 166.52 \\
\hline & (4980) & (2490) & (3423) & (4946) & (3534) & (2474) & (3534) & $(140.91)$ & (70.45) & (138.37) & (139.95) \\
\hline \multirow{2}{*}{$\begin{array}{l}\text { primary liver } \\
\text { cancer (median) }\end{array}$} & 10769 & 5385 & 2099 & 10636 & 3602 & 1590 & 3571 & 298.99 & 149.50 & 131.99 & 297.85 \\
\hline & (7977) & (3988) & (2099) & (7884) & (2827) & (1590) & (2827) & (282.15) & (141.06) & (131.99) & (278.86) \\
\hline$x^{2}$ & 127.87 & 127.00 & 3.66 & 135.47 & & & & & & & \\
\hline P & 0.0001 & 0.0001 & 0.45 & 0.0001 & & & & & & & \\
\hline
\end{tabular}


Table 6 The direct cost of all HBV-related diseases stratified by hospitals (dollar/per average annual admission)

\begin{tabular}{|c|c|c|c|c|c|c|c|c|}
\hline \multirow[t]{2}{*}{ Classification } & \multicolumn{2}{|c|}{ Tertiary hospitals } & \multicolumn{2}{|c|}{ Secondary hospitals } & \multicolumn{2}{|c|}{ Total } & \multirow[t]{2}{*}{$x^{2}$} & \multirow[t]{2}{*}{$P$} \\
\hline & No. & cost & No. & cost & No. & cost & & \\
\hline \multirow[t]{2}{*}{ Acute hepatitis B (median) } & 26 & 3135 & 3 & 1388 & 29 & 2954 & 4.31 & 0.0378 \\
\hline & & $(2830)$ & & (1598) & & (2464) & & \\
\hline \multirow[t]{2}{*}{ Severe hepatitis B (median) } & 28 & 10834 & 0 & - & 28 & 10834 & - & - \\
\hline & & (9697) & & & 449 & (9697) & & \\
\hline \multirow[t]{2}{*}{ Chronic hepatitis B (median) } & 385 & 4380 & 64 & 5588 & & 4552 & 12.12 & 0.0005 \\
\hline & & (3012) & & $(2131)$ & & (2919) & & \\
\hline \multirow[t]{2}{*}{ Compensated cirrhosis (median) } & 109 & 6022 & 12 & 19919 & 121 & 7400 & 0.08 & 0.7747 \\
\hline & & (3909) & & (4586) & & (4074) & & \\
\hline \multirow[t]{2}{*}{ Decompensated cirrhosis (median) } & 170 & 7107 & 32 & 6565 & 202 & 6937 & 1.99 & 0.1583 \\
\hline & & (5042) & & (4177) & & (4946) & & \\
\hline \multirow[t]{2}{*}{ Primary liver cancer (median) } & 56 & 10213 & 9 & 13268 & 65 & 10636 & 1.39 & 0.2390 \\
\hline & & (7595) & & $(11223)$ & & (7884) & & \\
\hline$x^{2}$ & & 115.20 & & 21.99 & & 135.47 & & \\
\hline$P$ & & 0.00 & & 0.00 & & 0.0001 & & \\
\hline
\end{tabular}

cost of those treated in secondary hospitals is significantly higher (5588 vs. $4380, \mathrm{p}<0.00$ ).

\section{Discussion}

Even with health insurance coverage, the direct costs of HBV-related diseases, except acute hepatitis B, exceeded $40.00 \%$ of household annual income in China, suggesting that HBV-related diseases should be placed categorized as catastrophic $[7,8]$. Due to the large amount of economic resources consumed, our results indicate that HBV-related diseases imposed a substantial economic burden on patients and their families in China $[9,10]$.

Our findings demonstrate that the direct economic burden of HBV infection increases as the disease progresses, with severe hepatitis B and primary liver cancer incurring expenses close to three times annual household income. By far the largest portion of direct costs, over 90 per cent, were medical in nature, consistent with $\mathrm{Li}$ et al.'s findings that $93.07 \%$ of direct costs were medical [6]. Much of the direct medical costs (84.86\%) were due to the costs of hospitalization, mainly due to drugs and examination fees which accounted for $77.49 \%$ of hospitalization costs.

Our study has several limitations. First, only tertiary and secondary hospitals were included in our survey. No township hospitals were sampled because the number of patients with HBV-related diseases in these hospitals was very small. Second, other than the direct medical cost for the current hospitalization, which was obtained from hospital financial data, all other outpatient and inpatient costs were self-reported and may be subject to recall error. Third, our data only allowed us to assess the direct inpatient cost of HBV-related diseases. We did not have data to estimate the direct outpatient cost of HBV-related diseases, nor were we able to evaluate the indirect cost of HBV-related diseases such as loss of productivity and income as a result of illness days and hospitalization, or loss of income for family members who were caregivers. In other words, the actual total economic burden of HBV-related diseases could be either higher or lower than our estimates. On the other hand, however, our survey only included patients who were hospitalized for seven or more days. These are likely patients with higher severity of illness which would cause upward bias in our estimations. Finally, our study does not capture the full burden of disease because it does not survey individuals infected with hepatitis B who were not hospitalized during the sampling period. Future research should address the important issue of estimating the overall economic burden of HBV-related diseases in China.

Our data indicated that median cost of chronic hepatitis B patients in secondary hospitals was significantly higher than those in tertiary hospitals. Considering the fact that patients with more severe illnesses and thus more costly patients would have been more likely to seek treatment at tertiary hospital, this result is alarming. This might be an indication of higher level of inefficiencies among secondary hospitals, as compared with tertiary hospitals. Clinical guideline is still under development in China, and hospital inefficiency has been a huge concern in the current hospital system. While tertiary hospitals attract the best resources, secondary hospitals in China are in a much more disadvantaged position and as a result, quality of care and efficiency could be much bigger issues. Our results call for the importance of implementing clinical 
guideline, improving system accountability, and helping secondary and smaller hospitals to improve efficiency. This has important policy implication for the on-going hospital reform in China.

\section{Conclusion}

Hepatitis B imposes considerable economic burden on a family. Our findings will help health policy makers' understanding of the magnitude of the economic burden of HBV-related diseases in China. Evidence from our study also contributes to our understanding of the potential benefits to society of allocating more resources to preventing and treating HBV infection, as well as increasing insurance coverage in China. For instance, patients with severe hepatitis B or primary liver cancer suffered a high economic burden even after insurance reimbursement, spending $137.45 \%$ and $149.50 \%$, respectively, of their household annual income. These findings have important policy implications for health care reform efforts currently underway in China focusing on how to reduce the burden of catastrophic disease for its citizens. In addition, overtreatment and over-medication are among the reasons for high personal costs in private facilities, given that government funding to public providers is insufficient. It is important to note that funds currently used for the unnecessary treatment of acute hepatitis B and for nutrition supplements could be redirected to programs designed to reduce the economic burden of HBV-related diseases.

\section{Consent}

Written informed consent was obtained from the patient for publication of this report and any accompanying images.

\section{Competing interests}

The authors declare that they have no competing interests.

\begin{abstract}
Authors' contributions
$J$ L, XA and JW conceptualized and supervised the study, contributed to the study design, made substantial contributions to the acquisition and qualityassurance of the data, and analyzed the data. $L Z, L S, R L, S Z$, and GZ contributed to the study design, survey conduction and supervision, as well as interpretation and writing of the manuscript. ML contributed to the statistical analysis, interpretation, writing and finalizing of the manuscript. All authors read and approved the final manuscript.
\end{abstract}

\section{Acknowledgement}

This study was supported by a grant from Chinese National Science and Technology Major Project(2008ZX10002-001 and 2009ZX10002-028)as well as Economics and Decision Evaluation of HBV-related Burden of Disease and Vaccination Strategies in Shandong Province(2009QW012). However, the authors will take all the responsibility of the study. We would like to acknowledge the support from doctors and nurses of Jinan infectious disease hospital, Shandong provincial hospital, Qingdao infectious disease hospital as well as other municipal or provincial 4 tertiary hospitals and 6 secondary hospitals. It has been approved by the Shandong Provincial Center for Disease Control and Prevention ethics committee under approval number. We would also like to thank Feng Ji, Jiaye Liu, Xuegiang Fang, Binyu Yan, Dawei Zhu, Zhen Wang, and Guojie Zhang for their field investigation and comments to the article context. The contents of this publication are solely the responsibility of authors.

\section{Author details}

${ }^{1}$ Center for Health Management and Policy in Shandong University, Jinan, Shandong 250012, China. ${ }^{2}$ Shandong Center for Disease Control and Prevention, Jinan, Shandong 250014, China. ${ }^{3}$ Shenzhen Center for Disease Control and Prevention, Shenzhen 51800, China. ${ }^{4}$ Department of Epidemiology and Biostatistics, Xi'an Jiaotong University College of Medicine, Xi'an, Shanxi 710049, China. ${ }^{5}$ Department of Economics, University of Calgary, Calgary, Alberta T2N4T4, Canada.

Received: 13 October 2011 Accepted: 24 January 2013

Published: 31 January 2013

\section{References}

1. Liang X, Bi S, Yang W, Wang L, Cui G, Cui F, Zhang Y, Liu J, Gong X, Chen Y, Wang F, Zheng H, Wang F, Guo J, Jia Z, Ma J, Wang H, Luo H, Li L, Jin S, Hadler SC, Wang Y: Epidemiological serosurvey of Hepatitis B in ChinaDeclining HBV prevalence due to Hepatitis B vaccination. Vaccine 2009, 27(1):6550-6557

2. Zhiqiang G, Zhaohui D, Qinhuan W, Dexian C, Yunyun F, Hongtao L, Iloeje UH: Cost of chronic Hepatitis B infection in China. J Clin Gastroenterol 2004, 38(10 Suppl 3):S175-S178.

3. Hu M, Chen W: Assessment of total economic burden of chronic Hepatitis B (CHB)-related diseases in Beijing and Guangzhou, China. Value Health 2009, 12(Suppl 3):S89-S92.

4. Yang BM, Kim CH, Kim JY: Cost of chronic Hepatitis B infection in South Korea. J Clin Gastroenterol 2004, 38(10 Suppl 3):S153-S157.

5. Harbarth S, Szucs T, Berger K, Jilg W: The economic burden of Hepatitis B in Germany. Eur J Epidemiol 2000, 16(2):173-177.

6. Li SC, Ong SC, Lim SG, Yeoh KG, Kwong KS, Lee V, Lee W, Lau J, Wong I, Kung N, Leung WT, Chan HL, Chan FK, Sung JJ, Lee KK: A cost comparison of management of chronic Hepatitis B and its associated complications in Hong Kong and Singapore. J Clin Gastroenterol 2004, 38(Suppl):S136-S143.

7. Xu K, Evans DB, Kawabata K, Zeramdini R, Klavus J, Murray CJ: Household catastrophic health expenditure: a multicountry analysis. Lancet 2003, 362:111-117.

8. Kawabata K, Xu K, Carrin G: Preventing impoverishment through protection against catastrophic health expenditure. Bull World Health Organ 2002, 80:612.

9. Liang S, Zhang SX, Qi-shan MA: Study on the Direct Economic Burden of Hepatitis B and its Economic Impact on Family in Shenzhen City. Chinese Health Economics 2011, 30(2):56-58.

10. Chen X, Chen H, Alison TM: Analysis of economic expense of Chronic Hepatitis B. Chinese J Hosp Adm 2003, 19(1):58-59.

\section{doi:10.1186/1472-6963-13-37}

Cite this article as: Lu et al.: Direct economic burden of hepatitis B virus related diseases: evidence from Shandong, China. BMC Health Services Research 2013 13:37.

\section{Submit your next manuscript to BioMed Central and take full advantage of:}

- Convenient online submission

- Thorough peer review

- No space constraints or color figure charges

- Immediate publication on acceptance

- Inclusion in PubMed, CAS, Scopus and Google Scholar

- Research which is freely available for redistribution 